\title{
Optimalisasi BUMDES Berbasis OVOP (One Village One Product) Concept Di Kabupaten Pamekasan
}

\author{
Firman Ardiansyah ${ }^{1}$, Nabila Yuli Firdaus ${ }^{2}$, Ridan Muhtadi ${ }^{3}$ \\ ${ }^{1 \& 2}$ Institut Agama Islam Negeri Madura \\ ${ }^{3}$ Institut Agama Islam Miftahul Ulum Pamekasan \\ firmanardiansyah1502@gmail.com ${ }_{2}$,nabilafirdaus07@gmail.com², \\ ridanmuhtadi@gmail.com ${ }^{3}$
}

\begin{abstract}
This study aims to provide a conceptual model regarding the optimization of Village-Owned Enterprises (BUMDES) based on the OVOP (One Village One Product) concept as a flagship program, which is every BUMDES in Pamekasan Regency forms a community that leads to integrated community economic empowerment order to optimizing superior commodities in Pamekasan Regency each village. This study uses descriptive qualitative methods with secondary data collection methods obtained from literature and documentaries that have been processed. While the data analysis technique starts from editing, organizing and finding. The results showed that this program has the potential to be realized, seeing the superior commodities owned by each village in Pamekasan Regency are very many and varied, in addition to support from the government regarding the priority of using the 2021 Village Fund for BUMDES, this program is the right step in overcoming existing problems. This program can be an alternative that is able to create food selfsufficiency in Pamekasan Regency as well as become one of the exporters of domestic products spread to national and international regions.
\end{abstract}

Keywords: BUMDES, OVOP concept, superior commodities.

\begin{abstract}
Abstrak: Penelitian ini bertujuan untuk memberikan model konseptual mengenai optimalisasi Badan Usaha Milik Desa (BUMDES) berbasis OVOP (One Village One Product) concept sebagai program unggulan, dimana setiap BUMDES di Kabupaten Pamekasan membentuk komunitas yang mengarah pada pemberdayaan ekonomi masyarakat secara terintegrasi guna mengoptimalkan komoditas unggulan pada desa masing-masing. Penelitian ini menggunakan metode kualitatif deskriptif dengan metode pengumpulan data sekunder yang diperoleh dari kepustakaan dan dokumenter yang telah diolah. Sedangkan teknik analisis datanya dimulai dari editing, organizing dan finding. Hasil penelitian menunjukkan bahwa program ini sangat potensial untuk direalisasikan, melihat komoditas unggulan yang dimiliki oleh masing-masing desa di Kabupaten Pamekasan sangat banyak dan beragam, selain itu dukungan dari pemerintah mengenai prioritas penggunaan Dana Desa tahun 2021 untuk BUMDES, program ini menjadi langkah yang tepat dalam mengatasi permasalahan yang ada. Program ini dapat menjadi alternatif yang mampu menciptakan kemandirian pangan di Kabupaten Pamekasan sekaligus menjadi salah satu daerah eksportir produk domestik tersebar ke wilayah nasional dan internasional.
\end{abstract}

Kata Kunci: BUMDES, OVOP concept, komoditas unggulan. 


\section{PENDAHULUAN}

Indonesia merupakan negara agraris yang memiliki sumber daya alam (SDA) yang sangat beragam dan melimpah. Selain itu lahan pertanian yang luas dan tanah yang subur menyebabkan mayoritas penduduk Indonesia bekerja di sektor pertanian (Mulyaningsih et al., 2018). Pada tahun 2020, Badan Pusat Statistik (BPS) menyebutkan bahwa jumlah penduduk yang bekerja di sektor pertanian menjadi mayoritas yakni sebanyak 38,23 juta jiwa dari total pekerja sebanyak 128,45 juta jiwa (Badan Pusat Statistik, 2020). Artinya, $29,76 \%$ penduduk Indonesia bekerja di sektor pertanian. Hal tersebut menjadikan sektor pertanian memiliki peranan penting dalam struktur pembangunan perekonomian nasional secara berkelanjutan.

Salah satu daerah yang memiliki potensi pertanian yang besar di Indonesia adalah Kabupaten Pamekasan. Pada tahun 2019, Kabupaten Pamekasan disiapkan menjadi lumbung pangan (Widyawati, 2019). Namun pencanangan tersebut sampai saat ini belum terealisasikan karena kualitas sumber daya manusia (SDM) di Kabupaten Pamekasan belum optimal, ditambah lagi adanya pandemi covid menyebabkan regulasi perekonomian menjadi semakin terhambat.

Berdasarkan arahan dari Rencana Tata Ruang Wilayah dan Masterplan Kawasan Agropolitan Kabupaten Pamekasan, sektor pertanian tersebut pengembangannya diarahkan pada kegiatan komoditas unggulan (Azwartika dan Sardjito, 2013). Akan tetapi, permasalahan utama pengembangan potensi desa untuk nantinya sebagai Demontration Plot (Demplot) program komoditas unggulan berlandaskan konsep OVOP (One Village One Product) adalah: 1) Sangat minimnya pengolahan produk, 2) Keterbatasan modal, 3) Pemasaran tidak efektif, 4) Kelembagaan dan kesinambungan produksi pengembangan tidak efisien, serta 5) Kurangnya pendampingan untuk pengembangan SDM (Kutsiyah, 2017).

Adanya permasalahan tersebut dibutuhkan solusi guna memajukan perekonomian di Kabupaten Pamekasan, salah satunya dengan mengoptimalkan BUMDES secara terintegrasi dengan memanfaatkan perkembangan teknologi informasi dan komunikasi yang dapat dilakukan secara efektif, efisien dan berkelanjutan. Upaya pengoptimalan BUMDES saat ini menjadi langkah yang tepat, dimana Kemenkeu (Wamen PDTT), Budi Arie Setiadi memaparkan prioritas penggunaan Dana Desa tahun 2021 diantaranya: untuk revitalisasi Badan Usaha Milik Desa (BUMDES) serta untuk pengembangan usaha ekonomi produktif yang dikelola oleh BUMDES (Setiadi, 2021).

Penulis memiliki solusi yang implementatif melalui program "POP-COIN: (Pamekasan OVOP Concept Integrated)", optimalisasi BUMDES berbasis OVOP (One Village One Product) Concept sebagai strategi pemberdayaan ekonomi masyarakat di Kabupaten Pamekasan. Program ini menjadi alternatif yang dapat menciptakan kemandirian pangan di Kabupaten Pamekasan sekaligus menjadi salah satu daerah eksportir produk domestik tersebar ke wilayah nasional bahkan internasional. Penelitian 
ini bertujuan untuk mendeskripsikan gambaran konsep "POP-COIN: (Pamekasan OVOP Concept Integrated)" sebagai solusi utama, serta mendeskripsikan langkah strategis pengimplemantasian inovasi program ini.

\section{METODOLOGI PENELITIAN}

Penelitian ini menggunakan metode penelitian kualitatif dengan pendekatan deskriptif. Menggunakan metode ini karena karya tulis yang diusung mempunyai tujuan untuk memperoleh gambaran mengenai kondisi permasalahan secara nyata dan cara penerapan solusinya dalam menangani permasalahan yang ada (Satori dan Komariah, 2013).

\section{Jenis Data}

Jenis data yang digunakan dalam penelitian ini adalah data sekunder. Data sekunder diperoleh secara tidak langsung melalui media perantara atau diperoleh dan dicatat oleh pihak lain (Sugiyono, 2008). Pada penelitian ini data sekunder diperoleh dari buku-buku dan artikel ilmiah yang dimuat di jurnal-jurnal serta dokumenter dari lembaga yang dapat dipercaya seperti Badan Pusat Statistik (BPS).

\section{Teknik Pengumpulan Data}

Teknik yang digunakan dalam pengumpulan data pada penelitian ini adalah (Ghofar, 1999):

1. Studi pustaka, yaitu serangkaian kegiatan yang berkenaan dengan metode pengumpulan data pustaka, membaca, mencatat serta mengolah bahan penelitian.

2. Dokumenter, studi dokumentasi dilakukan dengan membaca laporan-laporan penelitian sebelumnya serta artikel yang diakses dari internet dan buku dari lembaga yang dapat dipercaya.

3. Diskusi, yaitu cara pengumpulan data dengan melakukan pembicaraan dan pertukaran pikiran dengan orang-orang yang berkompeten dengan obyek yang sedang diteliti guna memecahkan masalah tertentu.

4. Intuitif-Subjektif, merupakan perlibatan pendapat penulis atas masalah yang sedang dibahas.

\section{Teknik Analisis Data}

Data-data yang telah dikumpulkan kemudian dikompilasikan sehingga diperoleh suatu konsep dengan langkah-langkah berikut (Diantha, 2017):

1. Editing: pemeriksaan kembali data yang diperoleh terutama dari segi kelengkapan, kejelasan makna dan keselarasan makna antara yang satu dengan yang lainnya.

2. Organizing: mengorganisir data yang diperoleh dengan kerangka yang diperlukan. 
3. Finding: melakukan analisis lanjutan tarhadap hasil pengorganisasian data dengan menggunakan kaidah-kaidah, teori dan metode yang telah ditentukan sehingga ditemukan kesimpulan yang merupakan jawaban dari permasalahan.

\section{Kerangka Berpikir}

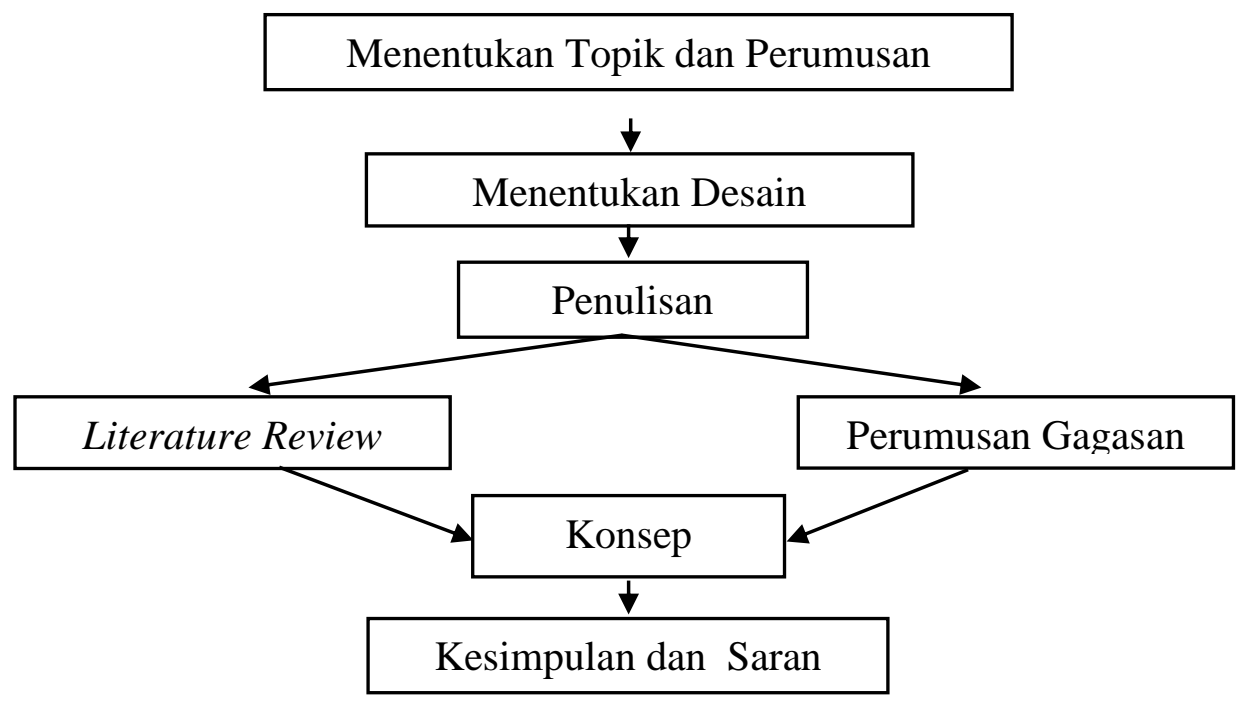

Gambar 1. Skema kerangka berpikir

\section{HASIL DAN PEMBAHASAN}

\section{A. Gambaran Program "POP-COIN" Sebagai Optimalisasi BUMDES Berbasis OVOP (One Village One Product) Concept.}

Pengembangan komoditas unggulan dan industri berbasis sumber daya lokal bisa melalui pendekatan OVOP (One Village One Product). Pendekatan ini merupakan gerakan masyarakat yang mengembangkan potensi yang dimiliki daerah secara integratif untuk meningkatkan pendapatan dan kesejahteraan masyarakat, meningkatkan rasa percaya diri, serta kebanggaan akan kemampuan sendiri pada daerahnya. Konsep OVOP sebagai suatu pendekatan pembangunan dari (endogenous development) yang memanfaatkan sebesar-besarnya potensi wilayah sebagai modal besar dengan tetap menjaga kelestarian lingkungan, sehingga dapat mengembangkan kearifan lokal (local wisdom) setempat dengan mendorong berkembangnya industri kecil dan menengah (BAPPEDA Kabupaten Pamekasan, 2020).

Konsep OVOP (One Village One Product) atau OVOC (One Village One Commodity) menjadi sebuah konsep kawasan komoditas unggulan yang melatar belakangi terbentuknya BUMDES di Indonesia. Penerapan konsep ini mengacu pada keberhasilan Jepang dan Thailand yang telah membuktikan keunggulan komparatif pada 
IMKA Implementasi Manajemen \& Kewirausahaan - Oktober, Vol. 1, No. 2, 153-164, 2021

konsep ini. Konsep sejenis ini di Thailand dikenal dengan istilah OTOP (One Tambon One Product) (Natsuda et al., 2011).

Berkaca pada keberhasilan Thailand dan Jepang, penerapan konsep OVOP di Indonesia diharapkan mampu mengatasi masalah kemiskinan yang tak kunjung usai, masyarakat akan memiliki sarana untuk mengoptimalkan produk lokalnya dan dapat menjadi badan usaha yang bersifat swakelola sehingga dapat menciptakan lapangan kerja dan mengurangi tingkat pengangguran. Pemberdayaan masyarakat berbasis pendekatan OPOP-OVOP-OVOC fokus utamanya adalah revitalisasi. Revitalisasi adalah sebuah upaya untuk menghidupkan kembali sesuatu yang dulunya pernah hidup dan terberdaya tetapi mengalami kemunduran atau degradasi dalam kurun waktu tertentu. Adapun skema revitalisasi konsep dasar OVOP sebagai berikut:

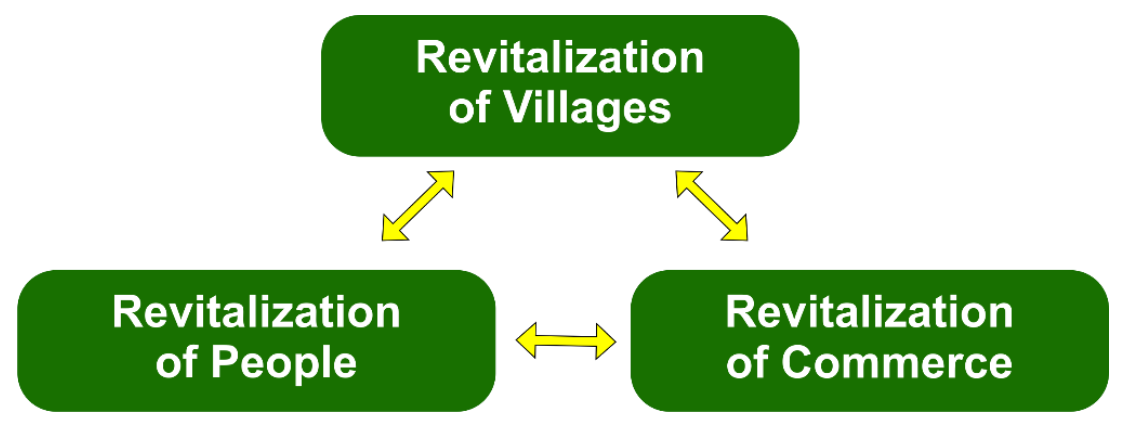

Gambar 2. Konsep Dasar OVOP

Gambar diatas menunjukkan bahwa terdapat tiga revitalisasi yang saling terintegrasi, yakni: 1) Revitalization of Village. 2) Revitalization of People, 3) Revitalization of Commerce. Program "POP-COIN: (Pamekasan OVOP Concept Integrated)" hadir sebagai bentuk revitalisasi tiga bidang ekonomi tersebut guna meningkatkan aksesibilitas terhadap produksi dan konsumsi produk domestik yang mendukung perekonomian secara berkelanjutan. Adapun bentuk revitalisasi tiga bidang ekonomi di Kabupaten Pamekasan adalah sebagai berikut:

\section{Revitalization of Village}

Revitalization of Village atau revitalisasi desa merupakan pemanfaatan segala potensi dan peluang yang ada di desa untuk meningkatkan produktivitas masyarakat yang dapat ditempuh melalui program pemberdayaan (endogenous development). Mengacu pada hasil penelitian yang dilakukan oleh (Kutsiyah, 2017) menunjukkan beberapa desa di Kabupaten Pamekasan memiliki komuditas produk unggulan sebagai berikut (Kutsiyah, 2017): 
Tabel 1. Desa yang diusulkan oleh SKPD sebagai target OVOP di Kabupaten Pamekasan, 2017

\begin{tabular}{llrr}
\hline No & Kecamatan & Desa & Komoditas Unggulan \\
\hline 1 & Tlanakan & Larangan Slampar & Cabe besar \\
2 & Pademawu & Tanjung, Pegagan, lembung & Rumput laut, mangrove, \\
& & garam \\
3 & Galis & Polagan & Ikan teri paron \\
4 & Larangan & Blumbungan & Cabe jamu \\
5 & Proppo & Klampar, Toket & Batik tulis \\
6 & Palengaan & Rekkerrek & Singkong \\
7 & Pegantenan & Pegantenan, Tebul Barat & Durian, jahe \\
8 & Kadur & Sokalelah, Kertagena Laok, & Pisang, ayam petelur, \\
& & Kadur, Pamoroh & jagung, semangka \\
9 & Pakong & Lebbek & Ikan lele \\
10 & Waru & Bajur & Lebah madu \\
11 & Batumarmar & Bangsereh, Kapong & Bawang merah, mete \\
12 & Pasean & Dempo Barat & Sapi bibit madura \\
\hline
\end{tabular}

Tabel diatas menunjukkan bahwa Kabupaten Pamekasan memiliki potensi keberhasilan yang besar untuk penerapan OVOP karena sumber daya alam yang dimiliki sangat beragam dan melimpah.

\section{Revitalization of People}

Revitalization of People atau revitalisasi manusia merupakan pemanfaatan dan peningkatan keahlian, keterampilan, dan kecakapan diri individu untuk lebih produktif dalam menjalankan aktivitas ekonomi. Revitalisasi manusia adalah usaha untuk membangun manusia (human capital). Program "POP-COIN" sebagai bentuk pemberdayaan masyarakat melalui pengembangan BUMDES, membentuk beberapa komunitas secara terintegrasi berdasarkan skill yang masyarakat miliki sehingga optimalisasi pemberdayaan ekonomi masyarakat desa melalui konsep komoditas unggulan ini dapat berjalan dengan baik. Masyarakat desa diklasifikasi sebagai berikut:

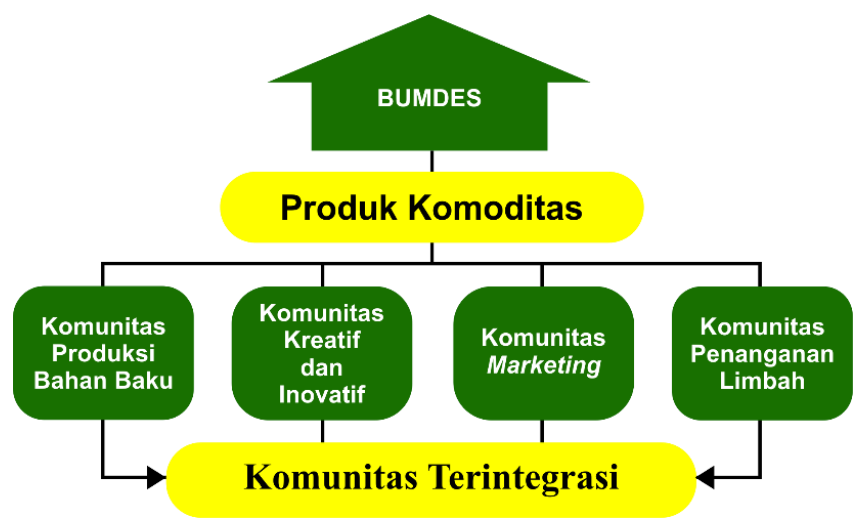

Gambar 3. Pemberdayaan Masyarakat Melalui Komunitas Terintegrasi 
a. Komunitas produksi bahan baku

Masyarakat memproduksi bahan baku dari masing-masing desanya. Dalam komunitas ini masyarakat diberikan pendampingan dan arahan secara intensif agar bahan baku yang diperoleh memiliki kualitas yang baik dan sesuai dengan permintaan dan kebutuhan masyarakat.

b. Komunitas kreatif-inovatif

Masyarakat mengolah hasil bahan baku yang telah diperoleh. Masyarakat yang menentukan produk yang akan dikembangkan sesuai kekhasan atau keunikan lokal yang dimiliki masing-masing desanya.

c. Komunitas marketing

Masyarakat mempromosikan inovasi produk yang telah dihasilkan. Hasil dari komunitas pemberdayaan yang telah terintegrasi ini akan dipromosikan melalui aplikasi "POP-COIN" agar masyarakat dapat dengan mudah bertransaksi dan mengetahui produk terbaru yang dihasilkan.

d. Komunitas penanganan limbah

Masyarakat melestarikan lingkungan di Kabupaten Pamekasan agar tidak tercemar oleh limbah-limbah hasil produksi. Melalui komunitas ini, limbah yang dihasilkan dapat diolah kembali menjadi sesuatu yang memiliki nilai jual, seperti dijadikan kerajinan tangan, pupuk, ataupun di daur ulang.

\section{Revitalization of Commerce}

Revitalization of Commerce atau revitalisasi perdagangan sebagai upaya menciptakan sistem ekonomi dalam desa yang dapat memenuhi kebutuhan sendiri (selfsufficient). Memasuki era society 5.0, pemasaran digital menjadi solusi untuk diterapkan sebagai bentuk revitalisasi perdagangan. Adanya upaya pemanfaatan teknologi digital karena pada era society 5.0 seperti sekarang memudahkan masyarakat untuk mengakses segala informasi menggunakan android atau IOS hanya dengan koneksi internet (Karinov, 2019). Program "POP-COIN" menyediakan sebuah aplikasi yang mengemas transaksi digital di bidang ekonomi dengan memasarkan hasil komoditas yang telah diolah oleh setiap komunitas pada masing-masing BUMDES di Kabupaten Pamekasan.

Aplikasi "POP-COIN" hadir dengan fitur-fitur canggih yang meliputi: Pilihan desa dan produk, profil desa, produk yang dihasilkan, rincian transaksi, dan metode pembayaran yang dapat diakses dalam satu aplikasi. Aplikasi ini menjadi sangat penting guna meningkatkan dan mempercepat regulasi perekonomian yang dapat menciptakan kemandirian pangan serta meningkatkan ekspor produk domestik yang berkelanjutan di Kabupaten Pamekasan. Adapun prototype aplikasi "POP-COIN", sebagai berikut: 

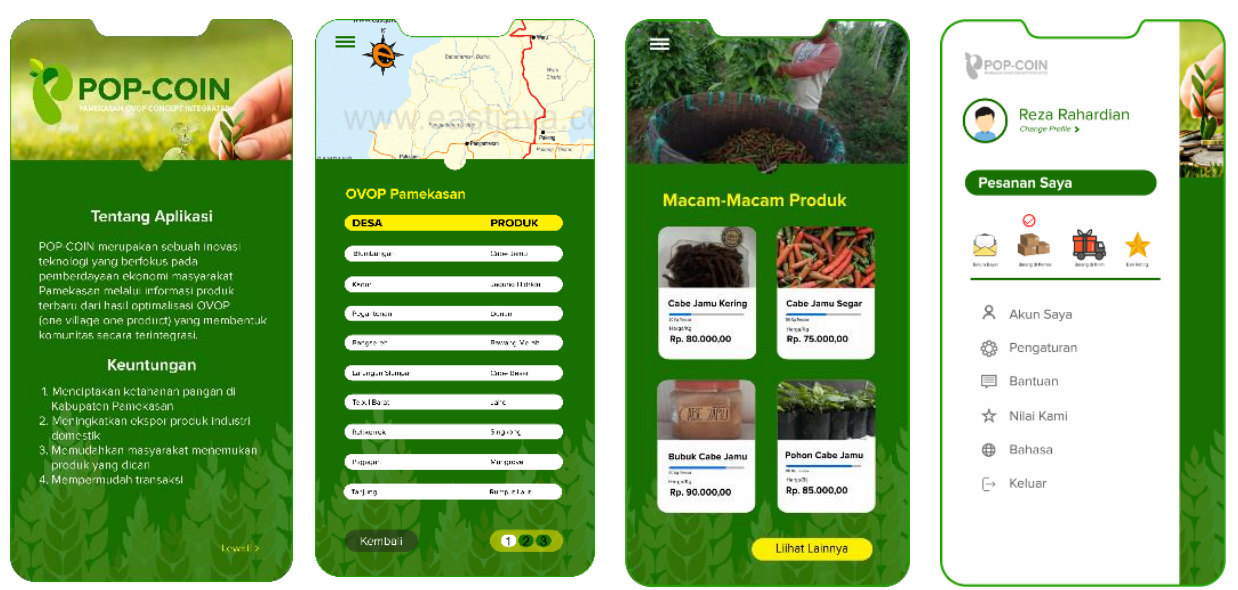

Gambar 4. Prototype Aplikasi "POP-COIN"

\section{B. Skema Operasional Program "POP-COIN"}

Program "POP-COIN" ini berada dibawah kendali BUMDES yang diawasi langsung oleh pemerintah, sehingga diharapkan pengawasannya dapat lebih mudah dan optimal. Adapun skema program POP-COIN adalah sebagai berikut:

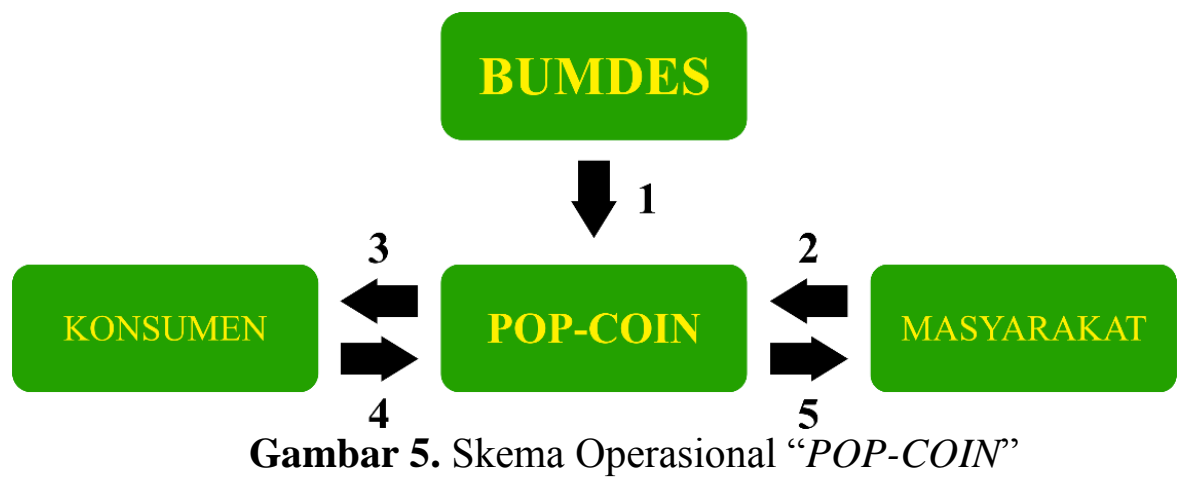

Keterangan:

1. BUMDES meluncurkan program "POP-COIN" kemudian mensosialisasikan kepada masyarakat.

2. Petani dan masyarakat mengajukan diri untuk bekerjasama pada program " $P O P$ COIN".

3. Pada program "POP-COIN", petani dan masyarakat akan diberdayakan melalui revitalisasi 3 bidang ekonomi.

4. Hasil produksi dari pemberdayaan tersebut dipasarkan langsung kepada masyarakat umum sebagai konsumen melalui aplikasi "POP-COIN".

5. Masyarakat umum sebagai konsumen dapat mencari dan membeli produk yang dibutuhkan melalui aplikasi "POP-COIN".

6. Hasil penjualan akan dikelola secara berkelanjutan, dan keuntungannya disalurkan pada masyarakat yang bekerjasama pada program "POP-COIN". 


\section{Potensi Keberhasilan Program "POP-COIN"}

Berikut penulis menjabarkan tiga potensi yang dapat menjadi faktor pendorong terealisasinya program "POP-COIN":

1. Dukungan dari Pemerintah

UU Cipta Kerja Nomor 11 Tahun 2020 menjadikan BUMDES sebagai badan hukum, dimana BUMDES menjadi investasi penting bagi desa untuk dapat terus menerus meningkatkan Pendapatan Asli Desa (PADes). Fungsi BUMDES adalah konsolidasi dan pemasaran produk desa (UU Cipta Kerja, 2020). Pengembangan BUMDES melalui program "POP-COIN" menjadi salah satu upaya yang tepat dalam rangka rebound ekonomi desa pada era society 5.0 ini.

2. Potensi dan Realisasi Dana BUMDES

Menurut Kemenkeu (Wamen PDTT), Budi Arie Setiadi memaparkan prioritas penggunaan Dana Desa tahun 2021, diantaranya: unuk revitalisasi Badan Usaha Milik Desa (BUMDES) serta untuk pengembangan usaha ekonomi produktif yang dikelola oleh BUMDES. Kedua program prioritas nasional tersebut sesuai kewenanga desa yang meliputi pendapatan desa, pemetaan potensi dan sumber daya, pengembangan teknologi informasi dan komunikasi, pengembangan desa wisata, penguatan ketahanan pangan dan pencegahan stunting di desa, serta desa inklusif, dan terakhir ialah adaptasi kebiasaan baru yaitu Desa Aman Covid-19 (Setiadi, 2021). Kemendes PDTT memprogram Sustainable Development Goals (SDGs) Desa yang bersisi 18 poin sejalan dengan SDGs Nasional (Iskandar, 2021). Pengembangan BUMDES melalui program "POP-COIN" dapat merealisasikan Dana BUMDES sehingga dapat mengurangi masyarakat kemiskinan, kelaparan, keterlibatan perempuan, dan meningkatkan pertumbuhan ekonomi yang merata.

3. Memberikan Feedback bagi Masyarakat

Meningkatnya kuantitas output dari produksi yang dihasilkan oleh program " $P O P$ COIN", maka apabila mengacu pada hukum ekonomi permintaan, hal tersebut bisa menurunkan harga output, ceteris paribus. Ini merupakan umpan balik dari program "POP-COIN" dimana masyarakat mendapatkan harga yang lebih murah dari hasil produksi domestik.

\section{Stakeholders Pengimplementasian Program "POP-COIN"}

Pihak-pihak yang terlibat dalam program "POP-COIN", dalam hal ini menggunakan konsep pentahelix yang merupakan kolaborasi antar lini:

1. Pemerintah, sebagai elemen yang bertindak sebagai pihak pendukung terhadap segala aktivitas program "POP-COIN" terutama koordinasi dan fasilitasi yang berkaitan dengan legalitas hukum operasionalnya. Pemerintah juga berperan sebagai team ahli yang memberikan pengawasasan dan pendampingan terkait revitalisasi program "POP-COIN" secara berkelanjutan. 
2. BUMDES, sebagai pusat dari segala kegiatan program "POP-COIN". BUMDES menempati posisi yang sangat penting sebagai subjek utama dalam meningkatkan laju perekonomian melalui program "POP-COIN".

3. Masyarakat, sebagai objek utama dalam membantu meningkatkan laju perekonomian melalui program "POP-COIN". Masyarakat, baik sebagai produsen maupun konsumen, menempati posisi yang sangat penting dalam menentukan keberhasilan dan keberlanjutan program ini.

4. Akademisi, sebagai elemen yang melakukan riset (researcher) atau penelitian untuk mengetahui secara komprehensif faktor-faktor yang mempengaruhi perekonomian masyarakat guna terus meningkatkan kualitas output dari adanya program " $P O P$ COIN".

5. Media, sebagai alat utama dalam melakukan transaksi pada aplikasi "POP-COIN" mempunyai peran yang sangat penting demi kelancaran inovasi. Media sebagai pencipta branding dan marketing produk-produk yang dihasilkan dari program "POP-COIN" baik kepada masyarakat lokal, nasional maupun international.

\section{E. Tahapan Implementasi}

Program "POP-COIN" tidak hanya untuk mengatasi masalah perekonomian, akan tetapi juga untuk mengurangi pengangguran di Kabupaten Pamekasan. Mengingat potensi dari gagasan ini, diperlukan persiapan yang matang untuk mengimplementasikan. Berikut merupakn tahapan implementasi program "POP-COIN":

Tabel 2. Tahapan Implementasi program "POP-COIN"

\begin{tabular}{|c|c|c|}
\hline No & Tahapan & Keterangan \\
\hline 1 & Tahap Konsepsi & $\begin{array}{l}\text { Tahap ini terdiri dari penguatan konsep program serta } \\
\text { identifikasi secara mendalam mengenai program " } P O P \text { - } \\
C O I N \text { " sehingga bisa dilakukan perencanaan jangka } \\
\text { panjang }\end{array}$ \\
\hline 2 & Tahap Persiapan & $\begin{array}{l}\text { Tahap ini meliputi perencanaan dan penyediaan segala } \\
\text { aspek kebutuhan untuk mengimplementasikan program } \\
\text { "POP-COIN" }\end{array}$ \\
\hline 3 & Tahap Koordinasi & $\begin{array}{l}\text { Tahap ini meliputi komonikasi, kerjasama, dan konfirmsi } \\
\text { antar pemangku kepentingan pada program "POP- } \\
\text { COIN" }\end{array}$ \\
\hline 4 & Tahap Implementasi & $\begin{array}{l}\text { Tahap ini meliputi sosialisasi program, dan memulai } \\
\text { operasional program "POP-COIN" }\end{array}$ \\
\hline
\end{tabular}

\section{Kesimpulan}

"POP-COIN: (Pamekasan OVOP Concept Integrated)" merupakan sebuah program secara terintegrasi melalui optimalisasi BUMDES berbasis OVOP (One Village One Product) Concept sebagai strategi pemberdayaan ekonomi masyarakat di Kabupaten 
Pamekasan. Penerapan program ini mengacu pada keberhasilan Jepang dan Thailand yang telah membuktikan keunggulan komparatif menggunakan konsep OVOP. Strategi dalam mengimplementasikan program "POP-COIN" menggunakan konsep pentahelix sebagai stakeholders. Hasil penelitian menunjukkan bahwa program "POP-COIN" merupakan solusi yang tepat sebagai langkah optimalisasi BUMDES, dimana pemerintah memprioritaskan penggunaan Dana Desa pada tahun 2021 untuk revitalisasi BUMDES. Penerapan konsep OVOP ini diharapkan mampu mengatasi masalah kemiskinan yang tak kunjung usai, sebab dengan adanya program ini masyarakat akan memiliki sarana untuk mengoptimalkan produk lokalnya, selain itu program "POP-COIN" dapat menjadi badan usaha yang bersifat swakelola yang mampu menciptakan lapangan kerja dalam upaya mengurangi tingkat pengangguran di Kabupaten Pamekasan.

Penelitian ini diharapkan dapat mendorong peneliti-peneliti lain untuk menganalisis lebih lanjut mengenai optimalisasi BUMDES berbasis OVOP (One Village One Product) Concept sebagai strategi pemberdayaan ekonomi masyarakat di Kabupaten Pamekasan.

\section{DAFTAR PUSTAKA}

Azwartika, R., \&. Sardjito, R. (2013). Pengembangan Komoditas Unggulan Pertanian dengan Konsep Agribisnin di Kabupaten Pamekasan. Jurnal Teknik Pomits, 2(2), 15-30.

Badan Pusat Statistik (BPS). (2020). "Persentase penduduk bekerja menurut lapangan pekerjaan”. Diakses melalui https://databoks.katadata.co.id pada tanggal 19 September 2021.

BAPPEDA Kabupaten Pamekasan. (2020). Profil One Village One Product.

Diantha, I. M.P. (2017). Metodologi penelitian hukum normatif. Jakarta: Prenada Media Group.

Ghofar, A. (1999). Analsis Implikasi Pemikiran dan Penafsiran Akuntansi dari Paradigma Mainstream Barat dan Paradigma Islam dalam Kerangka Analisis Konsep TAO. Skripsi (S1). Jurusan Akuntansi, Fakultas Ekonomi, Universitas Brawijaya, Malang.

Iskandar, A. H. (2021). "SDGs Desa". Diakses melalui https://sdgsdesa.kemendesa.go.id pada tanggal 02 Oktober 2021

Karinov. (2019). Revolusi industri 5.0 ala Jepang: Human-centered society. Diakses melalui https://karinov.co.id/revolusi-industri-5-jepang pada tanggal 11 September 2021

Kementrian Desa, Pembangunan Desa Tertinggal dan Transmigrasi. (2015). Peraturan Pendirian, Pengurusan dan Pengolahan, dan Pembubaran, Badan Usaha Milik 
Desa. Jakarta: Kementerian Desa, Pembangunan Desa Tertinggal dan Transmigrasi.

Kutsiyah, F. (2017). Performa desa yang diusulkan untuk penerapan one village one product (OVOP) di Kabupaten Pamekasan. IQTISHADIA: Jurnal Ekonomi dan Perbankan Syariah, 4(1), 25-41

Mulyaningsih, A., Hubeis, A.V.S., Sadono, D., \& Susanto, D. (2018). "Partisipasi petani pada usaha tani padi, jagung, dan kedelai perspektif gender. Jurnal Penyuluhan, 14(1), 145-158.

Natsuda, K. Wiboonpongse, A \& Cheamuangphan. (2012). One village one product rural development strategy in Asia: the case of OTOP in Thailand, RCAPS Working Paper, 33(3), 369-385

Rompas, J. (2015). Potensi Sektor Pertanian Dan Pengaruhnya Terhadap Penyerapan Tenaga Kerja Di Kabupaten Minahasa Selatan, Manado. Jurnal Berkala Ilmiah Efisiensi, 15(4), 33-45.

Satori, D., Komariah, A. (2013). Metodologi penelitian kualitatif. Bandung: Alfabeta.

Setiadi, A., B. (2021). Ini prioritas penggunaan Dana Desa 2021. Diakses melalui https://www.kemenkeu.go.id pada tanggal 22 September 2021

Sugiyono. (2008). Metodologi Penelitian Kuantitatif, Kualitatif Dan R\&B. Bandung: Alfabeta.

UU Cipta Kerja Nomor 11 Tahun 2020 pasal 117.

Widyawati, L. (2019). Kabupaten Pamekasan dipersiapkan menjadi lumbung pangan. Diakses melalui https://swadayaonline.com pada tanggal 20 September 2021 